\title{
Are we slaves to DSM? A South African perspective
}

"The best protection against wild over-diagnosis is to ignore DSM-5. It is not official. It is not well done. It is not safe. Don't buy it. Don't use it. Don't teach it". 1 These are the words of Allen Frances, Emeritus Professor of Psychiatry at Duke University, who was chairperson of the taskforce that developed DSM-IV. A scathing indictment of the diagnostic system adopted years ago by our psychiatric forbearers in South Africa (SA) - a system drilled into the minds of students and trainee mental health professionals; adhered to religiously by the pharmaceutical industry and by health management organisations for reimbursement purposes; and cited in our courts of law to support the cause of justice in our country.

If Frances' advice does not concern us, then a recent statement by the director of the National Institute of Mental Health (NIMH), Thomas Insel, should cause us to stop dead in our tracks and ask 'What are we doing? Why have we been so blind? How did we go so wrong?' In a statement issued just two weeks before the official publication of DSM-5 by the American Psychiatric Association (APA) on the 18th May 2013, Insel announced "NIMH will be re-orienting its research away from DSM categories. Going forward, we will be supporting research projects that look across current categories - or sub-divide current categories - to begin to develop a better system ... What does this mean for patients? We are committed to new and better treatments, but we feel this will only happen by developing a more precise diagnostic system".?

For the director of NIMH to issue this devastating vote of no confidence on the eve of the manual's launch, suggests that something is seriously wrong. Our concern is that we mental health professionals in SA have not interrogated our loyal obedience to the DSM system and seem prepared to accept the 5th edition unquestioningly. With the new manual available on the shelves later this month at a staggering R2500, we seem prepared to prescribe it to our students as a core text, train and examine our registrars entirely in terms of its diagnostic categories and criteria, continue to base our evaluation and management of patients on its checklists, and hold it up as the gold standard diagnostic system for psychiatric research. Why are we not questioning and reviewing our reliance upon, and our apparent unwavering faith in, the DSM system, especially at a time when a new revised version is imminent? Is it because we believe it is scientifically sound? Is it because we are conformist to psychiatric tradition in SA? Or is it because we are complacent and don't wish to upset something so entrenched

Correspondence

Prof JK Burns

email: Burns@ukzn.ac.za within our professional identities, beliefs and practice as psychiatrists? And the skeptic might add: Is it because there are too many vested interests tied up in maintaining DSM hegemony in SA?

So, why are Frances and Insel and countless others warning us not to accept and follow the new DSM-5 blindly? There are a host of reasons:

\section{Concerns about reliability and validity}

Firstly, there are good reasons to question the validity of DSM-5 categories and criteria. As Insel says "the weakness is its lack of validity. Unlike our definitions of ischaemic heart disease, lymphoma, or AIDS, the DSM diagnoses are based on a consensus about clusters of clinical symptoms, not any objective laboratory measure. In the rest of medicine, this would be equivalent to creating diagnostic systems based on the nature of chest pain or the quality of fever". ${ }^{2}$

Furthermore, the testing and scientific review process in the development of DSM-5 was deeply flawed, casting serious doubt on the validity of the revised classifications and criteria. The DSM-5 field trials were designed for implementation in two stages; the first was intended to address reliability, the second quality control. The first field trials revealed significant problems and lack of reliability. Despite this, the second stage of the field trials was cancelled due to delays in the development process and pressure from the APA to publish to recoup the \$25 million spent on the revision process.

In early 2012, an Open Letter was addressed to the DSM5 Taskforce and the APA, appealing for an external scientific review of the DSM-5 proposals by an independent group of researchers who were not affiliated with DSM-5 or the APA. ${ }^{3}$ This letter was endorsed by more than 14,000 individuals and over 50 professional organizations, including 16 divisions of the American Psychological Association. Despite this (and many other) appeals, the APA Board refused to conduct an external scientific review; thus falling short of even the basic standards of independent peer review required by scientific journals.

Additional concerns about the DSM-5 development process that cast doubt on its validity include the following: No primary care or general practice professionals were involved in the field trials, despite the fact that they provide the majority of mental health treatment and prescribe the majority of psychiatric medications $s^{4,5}$; A public relations firm (GYMR) was hired to influence public opinion about the manual through a PR website (http://dsmfacts.org/).

Thus, we argue, there are several aspects of the DSM-5 development process that reflect an apparent prioritization of institutional needs above patient safety and general public welfare. 


\section{Threats to patient safety}

In many instances, DSM-5 includes changes that will have the effect of lowering diagnostic thresholds for disorders. In addition, there are new diagnostic categories, many of which do not have sufficient empirical backing. The authors of the Open Letter argue that "Increasing the number of people who qualify for a diagnosis may lead to excessive medicalization and stigmatization of transitive, even normative distress". 3 This, according to a Statement of Concern issued by another group of mental health professionals, "may compromise patient safety". 6

Examples of just some of these changes include the following:

- The removal of major depressive disorder's bereavement exclusion, which currently prevents the pathologisation of grief, which is a normal life process. Normal grief will now easily become major depressive disorder.

- The reduction in the number of criteria necessary for the diagnosis of attention deficit hyperactivity disorder, a diagnosis that, as Frances puts it, "is already subject to epidemiological inflation".?

- "Excessive eating 12 times in 3 months is no longer just a manifestation of gluttony and the easy availability of really great tasting food. DSM-5 has instead turned it into a psychiatric illness called Binge Eating Disorder".?

- First time substance abusers will be diagnostically grouped together with long-term addicts despite their very different treatment needs and prognosis. Frances points out that this will lead to unnecessary stigmatisation of the former group. ${ }^{7}$

Several specific changes, if misused by clinicians, may threaten the welfare of vulnerable groups such as children and the elderly. As Frances puts it so eloquently, "the everyday forgetting characteristic of old age will now be misdiagnosed as Minor Neurocognitive Disorder, creating a huge false positive population of people who are not at special risk for dementia". ${ }^{7}$ He warns us: "The history of psychiatry is littered with fad diagnoses that in retrospect did far more harm than good". ${ }^{7}$

\section{Specific concerns in relation to children and adolescents}

The implications of DSM-5 changes for children and adolescents are of particular concern and have attracted significant criticism from the scientific community. For example, Knoll et al ${ }^{8}$ argue that developmental and cultural aspects of anorexia nervosa are not sufficiently covered in DSM-5; while, in relation to elimination disorders, von Gontard $^{9}$ views DSM-5 definitions based on duration and frequency of wetting episodes as "arbitrary agreements." The new diagnosis of 'disruptive mood dysregulation disorder' threatens to label and treat children with temper tantrums, and provides an inadequate approach to irritability in children. ${ }^{1,10}$ Finally, concerned clinicians and researchers have drawn attention to the "callous and unemotional" specifier added to conduct disorder, warning that this may exacerbate the stigma already experienced by these children. ${ }^{11}$

\section{Conflicts of interest}

Despite protestations to the contrary, the development of DSM-5 has been a process inextricably linked to the interests of several highly influential third parties. Notably, over 70\% of Taskforce members declared a relationship with the pharmaceutical industry - these relationships cannot simply be dismissed because members were required to declare them. Furthermore, one cannot deny that the 'DSM project' is a fantastically lucrative business success for the APA, earning the organisation $\$ 5$ million a year and a cumulative amount of over $\$ 100$ million to date. If ever there was a textbook that has remained a best-seller for decades, it is the DSM. As Frances puts it, "There is an inherent and influential conflict of interest between the DSM-5 public trust and DSM-5 as a best seller". ${ }^{7}$

Why do we use DSM in South Africa?

It is not clear when and why a decision was taken by the psychiatric fraternity in South Africa to adopt DSM as our diagnostic system. Was this a consensus decision or a decision made by a few? What was the rationale (if any)? These are relevant questions, since this 'tradition' of ours places us in the global minority. In a global survey of nearly 5000 psychiatrists in 44 countries, only $23 \%$ stated that they use DSM for diagnostic classification in clinical practice. ${ }^{12}$ Seventy percent reported using the International Classification of Diseases (ICD). When one considers that South Africa is a WHO member state, and that within South Africa public health practitioners and institutions are required by law to report clinical 'cases' using the ICD-10 coding system, these questions take on particular relevance. Another important question is the following: How many South African or other African psychiatrists took part in the DSM-5 field trials? How do we know whether this system is valid within an African, 'developing country' context? And one final question: Why do we blindly continue to choose to be among the global few who use a diagnostic system that has a torrid history of attracting massive public criticism and distrust?

\section{Why we should use ICD in South African psychiatry}

There are seven good reasons why we should reconsider the DSM consider adopting the ICD system of psychiatric classification in South Africa:

1. The ICD is an international classification system developed by the WHO and used by its 194 member states; WHO is an organization that has an expressly public health agenda and global credibility.

2. The development of ICD and its revised editions is a highly consultative process, with full international representation on the task teams; with applicability to cross-cultural settings identified as one of its key priorities. (Note: ICD allows special adaptations (procedural codes) within those countries that deem it necessary).

3. ICD provides descriptive 'prototypes' to guide diagnosis, rather than arbitrary checklists of criteria that have dubious validity.

4. In South Africa, public health practitioners and institutions are required by law to report clinical 'cases' using the ICD-10 coding system.

5. In the private sector in South Africa, medical insurance companies require practitioners to code their patients using the ICD-10 system. 
6. The development and revisions of ICD entail a significant overall investment in the process and there are no financial gains reaped by that institution from its publication and distribution; thus conflicts of interest are virtually non-existent. Ethically, it should be the preferred choice.

7. Finally, unlike DSM (as discussed above), ICD has not attracted widespread criticism.

In conclusion, the publication of DSM-5 this month should spur us to re-think our allegiance to this diagnostic system. We do not have to continue to teach it, and use it clinically, just because this is our inherited 'tradition' in South African psychiatry. Surely, as a fraternity of professionals who place great value on scientific rigour and the welfare of our patients and their families, we owe it to them and to ourselves to reexamine our choices and our practices. Especially when that choice pertains to the manner in which we determine their mental health and the treatments we give them.

JK Burns', O Alonso-Betancourt²

'Department of Psychiatry, Nelson Mandela School of Medicine, University of KwaZulu Natal, Durban, KwaZulu Natal, South Africa

2Department of Psychiatry, Walter Sisulu University, Mthatha, Eastern Cape Province, South Africa

\section{References}

1. Frances A. Does DSM-5 have a captive audience? Huffington Post.(2013) http://www.huffingtonpost.com/allen-frances/doesdsm-5-have-a-captive_b_3080553.html (Accessed 07/05/2013).

2. Insel T. Transforming diagnosis. National Institute of Mental Health. 2013 http://www.nimh.nih.gov/about/director/2013/transformingdiagnosis.shtml. (Accessed 07/05/2013)

3. Open Letter to the DSM-5 . (2012)

http://www.ipetitions.com/petition/dsm5/ (Accessed 07/05/2013).

4. Wang PS, Aguilar-Gaxiola S, Alonso J, et al. Use of mental health services for anxiety, mood, and substance disorders in 17 countries in the WHO world mental health surveys. Lancet 2007; 370(9590): 841-850

5. Mark TL, Levit KR, Buck JA. Datapoints: psychotropic drug prescriptions by medical specialty. Psychiatric Services 2009; 60 (9): 1167

6. Is the DSM-5 safe? Statement of Concern about the Reliability, Validity, and Safety of DSM-5. 2012

http://dsm5response.com/statement-of-concern/ (Accessed 07/05/2013)

7. Frances A. DSM-5 is a guide, not a bible: Simply ignore its 10 worst changes. Huffington Post 2012;

http://www.huffingtonpost.com/allen-frances/dsm-

5_b_2227626.html (Accessed 07/05/2013).

8. Knoll S, Bulik CM, Hebebrand J. Do the currently proposed DSM5 criteria for anorexia nervosa adequately consider developmental aspects in children and adolescents? Eur Child Adolesc Psychiatry 201 1; 20: 95-101

9. von Gontard A. Elimination disorders: a critical comment on DSM-5 proposals. Eur Child Adolesc Psychiatry 201 1; 20: 83-88.

10. Stringaris A. Irritability in children and adolescents: a challenge for DSM-5. Eur Child Adolesc Psychiatry 201 1; 20: 61-66.

11. Mao AR, Yen J. Review of proposed changes in Child and Adolescent Psychiatry Diagnostic Criteria for DSM-Version 5. Child \& Adolescent Psychopharmacology News 2010; 15(3): 1-8.

12. Reed GM, Correia JM, Esparza P, Saxena S, Maj M. The WPAWHO global survey of psychiatrists' attitudes towards mental disorders classification. World Psychiatry 2011; 10 (2): 118-131.

\title{
INSTRUCTIONS FOR AUTHORS African Journal of Psychiatry (AJP)
}

\section{Www.ajop.co.za}

All manuscripts and correspondence should be emailed to:

\author{
Professor CP Szabo,
}

email: christopher.szabo@wits.ac.za 